\title{
O MITO DE TUKU PARARÃ Í: EXPLICANDO A AGRESSIVIDADE TERRITORIAL E AMBIENTAL DOS “BRANCOS” (JURUÁ) E A ONTOLOGIA DA PAISAGEM ATUAL
}

Orestes Jayme Mega ${ }^{1}$

\section{RESUMO}

A proposta deste artigo é mostrar a relação existente entre aspectos ambientais da paisagem e aspectos da mitologia Mbyá-Guarani. A pesquisa foi realizada na aldeia MbyáGuarani denominada Tekoá Tavaí, localizada no município de Cristal, estado do Rio Grande do Sul. Na pesquisa foi utilizada uma abordagem teórica baseada nas ideias do arqueólogo norte-americano Severin Fowles, que caracteriza a arqueologia como a ciência das "grandes narrativas" (ALBERTI et al., 2011). Como resultado da pesquisa, foi verificado que os Mbyá-Guarani que residem na Tekoá Tavaí entendem as mudanças nas condições ambientais da paisagem em que vivem através da agência de entidades espirituais relacionadas à mitologia Mbyá-Guarani.

PALAVRAS-CHAVE: mitologia, paisagem, Mbyá-Guarani, grandes narrativas, entidades espirituais.

\section{ABSTRACT}

The purpose of this article is to show the existing relation among environmental aspects of the landscape and aspects of the Mbyá-Guarani mythology. The research was realized in the Mbyá-Guarani village called Tekoá Tavaí, located in the municipality of Cristal, state of Rio Grande do Sul, Brazil. In the research it was used a theorical approach based on the ideas of the American archaeologist Severin Fowles, that defines the archaeology as the science of the "great narratives" (ALBERTI et al., 2011). As results of the research it was verified that the Mbyá-Guarani that live in the Tekoá Tavaí understand the changes in the environmental conditions of the landscapes they live through the agency of spiritual entities related to the Mbyá-Guarani mythology.

1 Bacharel em Arqueologia e Preservação Patrimonial pela Univasf, Mestre em Antropologia pela UFPEL e Doutorando em Antropologia com área de concentração em Arqueologia pela UFPEL. E-mail: orestes_mega@yahoo.com.br. Orcid: http//orcid.org/0000-0003-0749-1829. 
Revista de Arqueologia Pública

KEYWORDS: mithology, landscape, Mbyá-Guarani, great narratives, spiritual entities.

\section{RESUMEN}

El propósito de este artículo es mostrar la relación existente entre aspectos ambientales del paisaje y aspectos de la mitología Mbyá-Guarani. La investigación fue realizada en el pueblo Mbyá-Guarani denominado Tekoá Tavaí, localizado en el municipio de Cristal, estado del Rio Grande do Sul, Brasil. En la investigación fue utilizada una abordaje teórica basada en la ideas del arqueólogo estadounidense Severin Fowles, que caracteriza la arqueología como la ciencia de las "grandes narrativas" (ALBERTI et al., 2011). Como resultado de la investigación, fue verificado que los Mbyá-Guarani que viven en la Tekoá Tavaí entienden los cambios en las condiciones ambientales del paisaje en que viven a través de la agencia de las entidades espirituales relacionadas a la mitología Mbyá-Guarani.

PALABRAS CLAVE: mitología, paisaje, Mbyá-Guarani, grandes narrativas, entidades espirituales.

\section{INTRODUÇÃO}

Este artigo consiste numa adaptação de um subcapítulo de minha dissertação de mestrado intitulada Paisagem e Mitologia Mbyá Guarani: Ecologia Simbólica da Tekoá Tavaí, Cristal, Rio Grande do Sul. A dissertação foi apresentada na Universidade Federal de Pelotas em junho de 2016. A pesquisa de campo referente a esta dissertação foi realizada na aldeia Mbyá-Guarani denominada Tekoá Tavaí, localizada no município de Cristal, RS. O objetivo de minha pesquisa na Tekoá Tavaí era o de relacionar aspectos da paisagem com elementos da mitologia Mbyá-Guarani.

A Tekoá Tavaí está localizada às margens da estrada BR-116 e possui uma área de 251 hectares. A atual presença Mbyá-Guarani na área data de dezembro de 2013. Na época de minha pesquisa de campo, que consistiu em vários períodos de estadia e visitas à aldeia durante os anos de 2015 e 2016, a população Guarani da área era de cerca de 26 pessoas, divididas em três kuery (grupos familiares).

Os procedimentos de campo adotados foram os de entrevistas semiestruturadas, a observação participante e a observação flutuante. Durante a pesquisa, tive como principais 


\section{Revista de Arqueologia Pública}

interlocutores o cacique José de Souza e um Mbyá proveniente de Salto do Jacuí, chamado Ramón. Também realizei entrevistas com outros Mbyá então residentes na Tekoá Tavaí que, de modo geral, confirmaram as informações de meus principais interlocutores.

\section{OS MBYÁ-GUARANI}

Existe uma ampla literatura a respeito dos Mbyá-Guarani e dos povos Guarani de um modo geral. Entretanto, neste artigo eu foquei naqueles autores que abordaram, direta ou indiretamente, a questão a ser analisada.

Os Mbyá-Guarani constituem um grupo indígena que habita os atuais territórios do Brasil, Paraguai, Uruguai e Argentina. No Brasil, os Mbyá-Guarani habitam, sobretudo, as regiões sul e sudeste do país (com exceção do estado de Minas Gerais), embora alguns poucos indivíduos Mbyá possam ser encontrados em outras regiões brasileiras (LITAIFF, 1996). É um grupo cujo idioma pertence à família Tupi-Guarani e que possui laços linguísticos e culturais com outras populações Guarani tais como Kaiowá e Nhandeva, embora constitua um grupo étnico independente e que possui como uma de suas principais características a mobilidade de seus membros através de suas diferentes localidades de habitação, que são conhecidas como tekoá.

As tekoá, para além disso, são também lugares propícios para se viver em conformidade com o modo de ser Mbyá-Guarani. As tekoá proporcionam não apenas um espaço de interação entre pessoas, animais, vegetais etc., mas também a interação com espíritos e divindades. Estas interações fazem parte do cotidiano Mbyá e são consideradas como elementos constituintes da paisagem e não algo que está além dela. Um dos exemplos destas interações é aquele realizado nas roças Mbyá, onde as divindades relacionadas a alguns alimentos tradicionais tais como o avaxi (milho), o kumanda (feijão), a jety (batata-doce) etc., fazem-se presentes. Estas entidades espirituais são denominadas já e são consideradas como "donos" dos alimentos. A citação abaixo esclarece melhor esta situação:

(...) é interessante notar que a roça, para o Mbyá-Guarani, é um espaço extremamente importante, digno de todas as atenções. A roça é um ambiente onde a força e o poder sobrenatural se fazem presentes - grosso modo, as divindades estão plantadas lá. Considerando as características da horticultura Mbyá-Guarani, onde várias espécies dividem o mesmo terreno, podemos especular que a força de diversos "donos" se fundem neste ambiente. Se por um lado misturar espécies é aumentar o rendimento dos alimentos cultivados pela "cooperação" das diferentes plantas, por 
outro lado ao semear diferentes plantas (com diferentes já) os MbyáGuarani estão aumentando o leque de forças sobrenaturais que incidem sobre o terreno. Enfim, a roça é um lugar "sagrado" para os Mbyá-Guarani. (TEMPASS, 2010, p. 118).

Contudo, a partir da ocupação de seu território tradicional por colonos europeus, o que ocasionou grandes transformações na flora e na fauna de suas paisagens tradicionais, os lugares propícios para se praticar os costumes Mbyá têm diminuído significativamente. Nesse sentido, a configuração atual das tekoá expressa a dinâmica histórica tanto dos colonizadores em reduzirem os Mbyá a áreas cada vez mais escassas, quanto a dos próprios Mbyá em garantirem sua sobrevivência cultural. Segundo o antropólogo José Otávio Catafesto de Souza:

(...) os grupos Guarani foram obrigados a abandonar seu habitat preferencial às margens pluviais, porque os rios tornaram-se disputados desde os tempos coloniais como caminhos de interiorização e suas margens serviam como ponta de lança capaz de consolidar a ocupação das terras limítrofes por vassalos dos impérios coloniais em disputa, ancestrais daqueles que se tornaram representantes dos países que, depois, conquistaram sua independência enquanto estados nacionais modernos. Expulsos dos rios, das terras transformadas em lavouras e em pastagens privadas, das matas abatidas, os Guarani recriaram seu sistema de vida ao longo dos séculos XIX e XX, exacerbando a mobilidade terrestre, a autonomia e divisão dos grupos domésticos em busca dos núcleos residuais de mata, exercitando um trânsito de famílias quase sempre reprimido pela aplicação regional da administração indigenista brasileira no sul, diretrizes políticas impulsionadas desde o Segundo Império até a penúltima década do século XX segundo o objetivo de concentrar e fixar os grupos indígenas em porções de terra diminutas, a fim de liberar áreas cada vez maiores para a implantação de lotes destinados a imigrantes europeus. (SOUZA, 2009, p. 4).

Neste sentido, vale lembrar que a atual situação fundiária dos Mbyá-Guarani os cerceia com muitas restrições, sendo estas consideradas como elementos que prejudicam a prática cotidiana da cultura Mbyá em sua integridade. Conforme Maria Inês Ladeira:

As áreas Guarani são pequenas, não contêm porções contínuas suficientes de mata para seu uso exclusivo e suas delimitações são definidas em função da ocupação do entorno e do modelo dessa ocupação. (LADEIRA, 2001, p. 123).

Tendo por base as transformações da paisagem, os Mbyá elaboraram mitos que visam explicar por que os juruá são tão agressivos em relação ao meio ambiente. Mais à frente apresento alguns destes mitos. 


\title{
ONTOLOGIA E NARRATIVA DA PAISAGEM
}

O arqueólogo Severin Fowles apresenta uma interessante discussão a respeito das relações entre ontologia e narrativas de origem. Para ele, tanto as ontologias indígenas quanto as ocidentais estão ancoradas em narrativas de origem, geralmente de caráter mítico, e que uma das formas mais efetivas do fazer arqueológico é o de reescrever as narrativas fundacionais do passado (2011). Neste sentido, Fowles define a arqueologia como a disciplina das grandes narrativas (2011). Portanto, de acordo com esta abordagem, para a melhor compreensão da ontologia de uma paisagem, faz-se necessário compreender as narrativas das origens que são contadas sobre ela.

No artigo intitulado "Worlds Otherwise": Archaeology, Anthropology, and Ontological Difference (2011), escrito em parceria entre Benjamin Alberti, Severin Fowles, Martin Holbraad, Yvonne Marshall e Christopher Witmore no qual cada autor apresenta seu ponto de vista particular sobre a questão, há uma interessante reflexão de Fowles a respeito de uma estratégia de estudo que se mostrou bastante útil para o objetivo do presente artigo:

\begin{abstract}
Uma estratégia seria a utilização da ligação crítica entre ontologia e cosmogonia. Considere a influente discussão de Viveiros de Castro (1992, $1998,2004 a)$ sobre o perspectivismo na qual a saliente diferença entre as ontologias amazônicas e ocidentais é mostrada como se originando de seus respectivos mitos de origem. Considerando que "nós" podemos entender a humanidade (cultura) como tendo evoluído de uma base animal (natureza), observa Viveiros de Castro que "eles" entendem a diversidade de corpos animais como tendo evoluído de uma base humana (veja também Descola 2009). A prioridade cosmogênica entre natureza e cultura, em outras palavras, é reversa, e isso tem necessárias consequências ontológicas. A principal observação que eu quero assinalar aqui é que tanto as tradições ontológicas amazônicas quanto as ocidentais estão ancoradas em narrativas (embora narrativas muito diferentes). $O$ mundo é como ele veio a ser. A ontologia provém das origens - ou ao menos é reconhecida através dos discursos mais amplos a respeito das origens. ${ }^{2}$
\end{abstract}

$2 \quad$ Tradução nossa do trecho original: One strategy would be to build from the critical link between ontology and cosmogony. Consider Viveiros de Castro's (1992, 1998, 2004a) influential discussion of perspectivism, in which the salient difference between Amazonian and Western ontologies is shown to arise out of their respective myths of origin. Whereas "we" may understand humanity (culture) as having evolved out of a base animality (nature), notes Viveiros de Castro, "they" understand the diversity of animal bodies as having evolved out of a base humanity (see also Descola 2009). The cosmogenic priority between nature and culture, in other words, is reversed, and this has necessary ontological consequences. The main observation I want to underscore here is that for both

\begin{tabular}{|l|l|l|l|l|l|l|}
\hline (C) Rev. Arqueologia Pública & Campinas, SP & v.11 & n.1 & p.39 & Julho/2017 & ISSN 2237-8294
\end{tabular}


Neste artigo pretendo me aprofundar na questão apresentada por Fowles a respeito da ligação entre mitos de origem e, portanto, grandes narrativas, com as paisagens sobre as quais estas narrativas são contadas. Se existe uma narrativa fundacional a respeito da ocupação da Mata Atlântica pelos colonizadores europeus, narrativa esta baseada em conquista territorial, exploração de recursos e domesticação de um ambiente hostil através da transformação ambiental, há também uma narrativa Mbyá-Guarani a respeito da mesma paisagem, mas baseada em mitologia. Portanto, para compreender as relações existentes entre os Mbyá-Guarani e as paisagens em que vivem, faz-se necessário conhecer suas grandes narrativas.

Em um artigo de Ivori J. Garlet e Valéria S. de Assis denominado Desterritorialização e reterritorialização: a compreensão do território e da mobilidade Mbyá-Guarani através das fontes históricas (2009, p. 41-42), encontra-se um trecho que demonstra o quanto as formas de ocupação da paisagem pelos juruá (aqueles que não são indígenas, mas especialmente os brancos) são entendidas pelos Mbyá como uma forma de agressividade e como esta agressividade tem uma raiz mítica:

\begin{abstract}
O território Mbyá, como de resto em todas as sociedades indígenas conhecidas, é justificado apoiando-se na memória, que é continuamente relembrada através dos mitos. No mito da criação da Primeira Terra, em que os Mbyá explicam sua relação com o território, percebe-se que a mesma é engendrada a partir da extremidade da vara insígnia de Ñanderu Ete Tenondegua. Na sequência cria uma palmeira eterna, colocada no Centro da Terra. Originalmente Nanderu Ete Tenondegua fez somente bosques, não havendo campos; para fazê-los mandou Tuku Pararã i/o gafanhoto verde. (...) Por outro lado, é perceptível como a matriz mítica permite a inclusão de novos elementos para a interpretação de eventos históricos, ou o que GALLOIS (1985: 44) denomina a "irrupção dos brancos na mitologia indígena". A forma como os Mbyá interpretam esta irrupção pode ser acompanhada nas narrativas feitas por Perumi. (...) Em ambos os textos pode-se acompanhar que, ao criar o mundo, o propósito de Ñanderu Tenondegua era de que seus filhos (Mbyá) e os brancos vivessem juntos e em harmonia. Mas os brancos se recusaram e exigiram que a terra fosse dividida. Diante do fato, Ñanderu Tenondegua destina a mata aos Mbyá e o campo aos brancos, ordenando que cada um vivesse nos seus limites. Mas os brancos logo transgrediram o pacto, invadindo as selvas e, tal qual o gafanhoto, "o'upa ka'aguy" comeram toda a mata, ou seja, removeramna para dar lugar aos campos e pastos para suas vacas. Este é um dos motivos apontados por Perumi para que se desencadeasse a saída dos Mbyá de seus lugares, partindo em busca de espaços onde novamente pudessem encontrar matas.
\end{abstract}

Amazonian and Western traditions ontology is anchored in narrative (albeit in very different narratives). The world is as it has come to be. Ontology springs from origins - or at least is reckoned through the larger discourse about origins. 
A partir do fragmento de mito contido na citação acima, na qual se explica a agressividade territorial e ambiental juruá através de sua ligação mítica com Tuku Pararã í (o gafanhoto verde), que implica, primeiramente, na criação de um espaço próprio e apartado para os juruá, com características bem diversas do espaço destinado aos Mbyá e, posteriormente, a quebra de um acordo territorial através de uma agressividade não apenas territorial mas também ecológica, pois em termos míticos, o juruá não é um habitante da mata (ka'aguy), mas um habitante dos campos e cidades e que sempre está acompanhado pela vaca, animal símbolo de uma fauna exógena e do avanço da pecuária sobre a Mata Atlântica e de seus efeitos destrutivos, fica claro que o juruá assume o papel de perturbador de uma ordem cósmica estabelecida pelo criador da Terra (Ñanderu Ete Tenondegua).
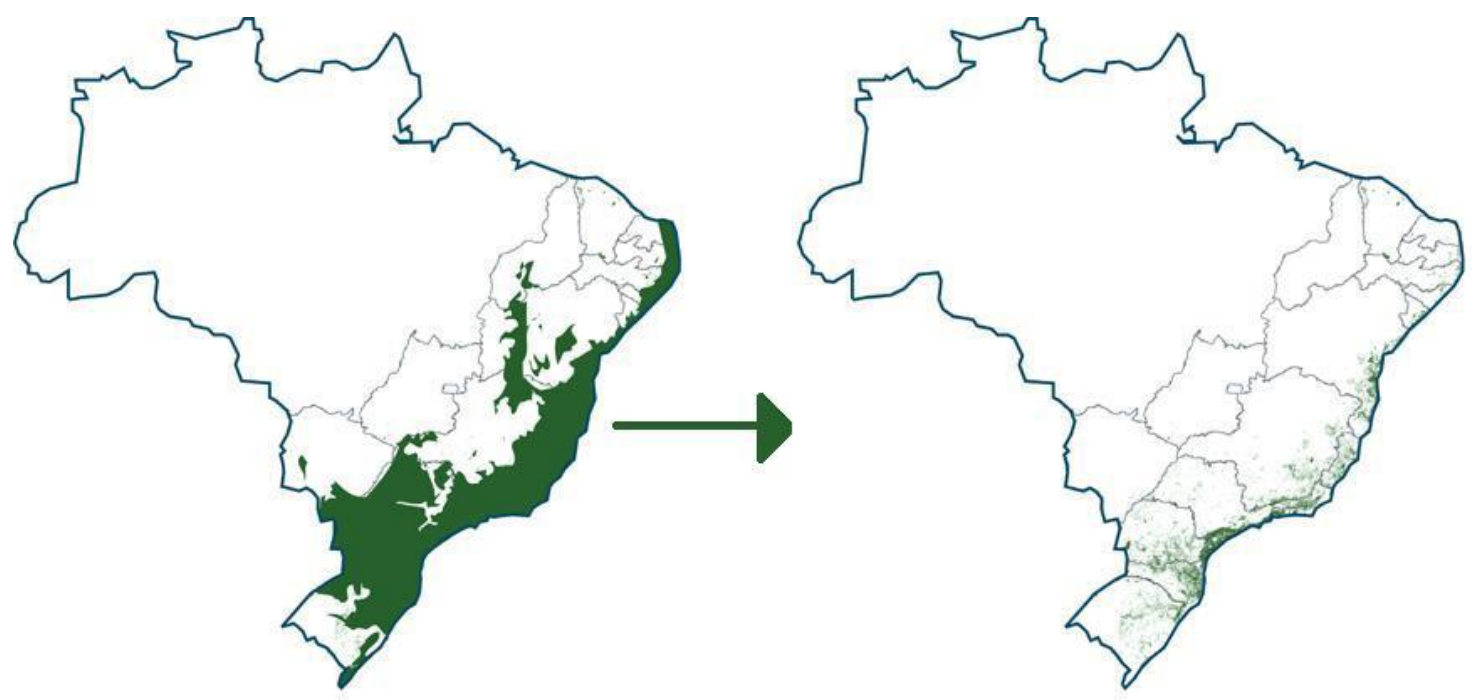

Imagem 1: Devastação da Mata Attântica. As áreas em verde no mapa da esquerda indicam a extensão original da Mata Atlântica. As áreas em verde no mapa da direita indicam as áreas remanescentes da Mata Atlântica atualmente. Fonte:<http://riosvivos.org.br/a/Noticia/Atlas+dos+Remanescentes+Florestais+da+Mata+Atl antica+/1567> (2016).

Desta forma, estabelecem-se pares de opostos que podem ser definidos da seguinte maneira:

- O Mbyá está para a mata assim como o juruá está para o campo; 
- O Mbyá está para a fauna nativa assim como o juruá está para a fauna exógena;

- O Mbyá está para a não-agressividade territorial e ambiental assim como o juruá está para a agressividade territorial e ambiental;

- O Mbyá está para a obediência à ordem cósmica de Ñanderu Ete Tenondegua, de respeitar o acordo originalmente feito, assim como o juruá está para a desobediência da ordem cósmica de Ñanderu Ete Tenondegua;

- O Mbyá está para o modo correto de ser (tekó porã), pois em conformidade com os desígnios de Nanderu, assim como o juruá está para o modo incorreto de ser (tekó vaî), pois contrário aos desígnios de Ñanderu.

Tal mito encontra um paralelo com outros mitos Mbyá colhidos por Daniel Calazans Pierri entre os Mbyá de São Paulo e reunidos em sua dissertação de mestrado intitulada: $O$ perecível e o imperecível: lógica do sensível e corporalidade no pensamento guarani-mbyá. De acordo com o mito da criação dos juruá, estes não são descendentes dos deuses, ao contrário dos Guarani, mas surgiram da transformação da mbi'i, a lagarta originária (PIERRI, p. 57). Portanto, o juruá não compartilha da mesma ancestralidade divina dos Mbyá, é uma criatura essencialmente diferente e que, desde seus primeiros feitos, têm mostrado uma agressividade ambiental que se materializa na paisagem pela abertura de campos para pecuária e monocultura. De acordo com outro mito colhido por Daniel Calazans Pierri:

Os Juruá [brancos] são muito ignorantes, são inferiores. Nhanderu primeiro criou os Guarani quando a terra ainda era plana e depois criou os Juruá que são feitos na própria terra, por isso os mais velhos falam yvyipo kuery (os que são feitos na própria terra) e também eta va'e kuery (os numerosos, excessivos). Mas mesmo assim Nhanderu Tenondé Papa falou para os Guarani e para os Juruá quando eles ainda eram crianças para eles criarem algum instrumento para viverem na terra, dando a escolha do mesmo jeito para os dois. Aí o Guarani criou o arco e flecha e com ele conseguia caçar alguns bichinhos e se sustentar, sem acabar com todos os bichos. E o juruazinho criou a arma de fogo e a metralhadora e assim caçava muito e acabava com todos os bichos. Depois Nhanderu falou para eles criarem algo para viverem da terra e o Guarani criou uma rocinha com um pouco de tudo, avaxi ete"i [milho], kumanda [feijão], manduvi [amendoim], xanjau [melancia] e o juruazinho criou uma plantação enorme de uma espécie só com trator que acabava com tudo e destruía o mato para vender. Então os campos eram para o Juruá fazer as plantações mas eles derrubavam o mato que era para o Guarani viver. Por isso o Juruá sempre foi assim muito materialista e o Guarani sabia fazer as coisas sem destruir. (PIERRI, 2013, p. 85-86).

Em minhas atividades de campo na Tekoá Tavaí, uma das informações mais 


\section{Revista de Arqueologia Pública}

enfatizadas pelo meu principal interlocutor, o cacique José de Souza, era a de que as áreas de campo, que ele denomina como inhu, são sempre uaikuê, isto é, são sempre ruins, pois é como se elas representassem a perturbação da ordem cósmica original.

Meu interlocutor confirmou-me o mito de Tuku Pararã í. Ele conhece o mito e vê a sua expressão material no avanço das áreas de inhu sobre as áreas de mata (ka'aguy). Há dez anos, ainda conforme as informações de meu interlocutor, havia muito mais ka'aguy e, portanto, muitos mais lugares para se viver conforme a tradicionalidade Mbyá-Guarani. Ele também falou do quão bom seria se a ka'aguy voltasse.

A tekoá Tavaí é, em sua maior parte, constituída por áreas de Mata Atlântica em regeneração. Estas áreas, há alguns anos, eram inhu, onde a fauna da Mata Atlântica estava quase que completamente ausente. A lenta e gradual regeneração da Mata Atlântica nestas áreas trouxe de volta alguns exemplares da fauna nativa. Em algumas de minhas visitas à Tavaí presenciei o voo rasante de alguns gaviões sobre minha cabeça. Os cágados também voltaram, assim como os teiús e os ratões do banhado. Entretanto, parte significativa da tekoá Tavaí continua sendo inhu.

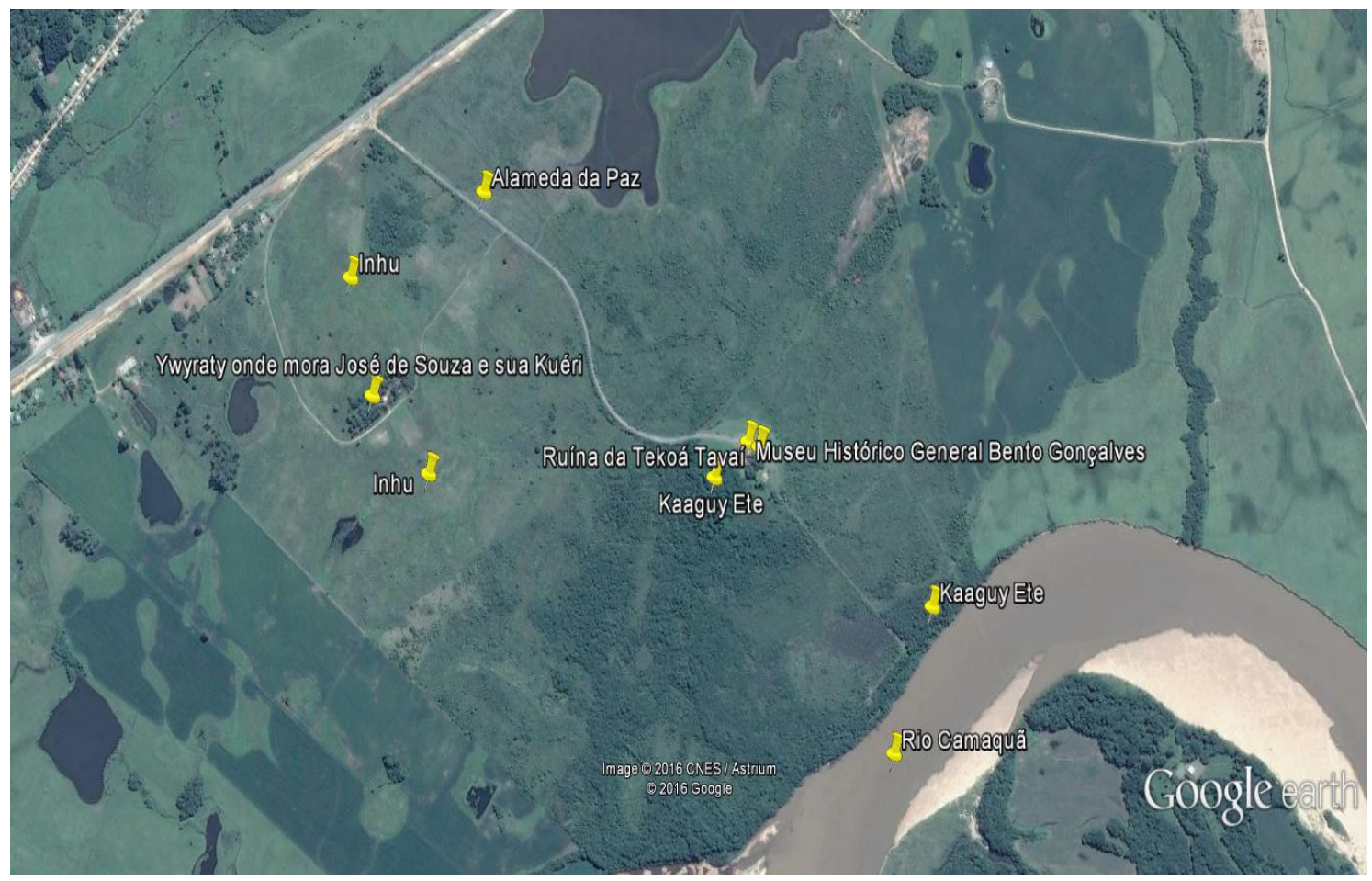

Imagem 2: Área da Tekoá Tavaí.

Fonte: Google Earth (2016). 
Um dado importante que obtive em campo foi o da presença de entidades espirituais nas áreas de inhu. Estas entidades são conhecidas como inhujá ou campojá. Os inhujá são entidades uaikuê, isto é, entidades ruins que estão intimamente relacionadas às paisagens construídas pelos juruá. Os inhujá são invisíveis, mas suas presenças são presumidas através dos mitos. Os Mbyá da tekoá Tavaí, que vivem cercados por áreas de inhu que circundam a tekoá, sabem que os inhujá estão nestes campos, embora não possam vê-los.

Devido ao fato das áreas de campo serem produtos de atividades juruá orientadas para se atingir objetivos socialmente determinados tais como estabelecer pastagens, podese, em alguns casos, relacionar estas áreas com as ações de Tuku Pararã ĺ em criar as primeiras áreas de inhu. Desta forma, o crescimento das áreas de inhu representa a continuidade de um ato de inimizade, pois os juruá se recusaram a conviver com os Mbyá na ka'aguy, onde ambos viviam originalmente, e de agressividade, já que os juruá não ficaram contentes com as áreas de inhu feitas por Tuku Pararã ĺ, mas se esforçam para adquirir mais áreas de inhu, destruindo o pouco que resta de ka'aguy. Tais fatos constituem um aspecto fundamental para a grande narrativa Mbyá a respeito de como o mundo veio a ficar assim, destituído de áreas suficientes de ka’aguy.

Outro fato interessante sobre os inhujá é que, devido às suas afinidades com as áreas de campo, eles não adentram nas áreas de ka’aguy e, portanto, há uma separação nítida entre os domínios de entidades espirituais com as quais os Mbyá preferem se relacionar, isto é, as entidades espirituais que vivem nas áreas de ka'aguy, e os domínios de entidades espirituais com as quais eles não gostam de se relacionar (os inhujá).

Além das áreas de campo, outros lugares que são intimamente ligados aos juruá, e que são igualmente uaikuê, são as cidades. As cidades pequenas os Mbyá denominam tetã í. A cidade de Cristal é um exemplo de tetã í. Entretanto, os Mbyá-Guarani residentes na tekoá Tavaí temem seu crescimento pois ela pode se tornar uma tetã guaçu, isto é, uma cidade grande.

As tetã também são habitadas por entidades uaikuê denominadas de tetãjá. Meu interlocutor demonstrou uma grande preocupação pelo crescimento das cidades. Sua principal preocupação é com o crescimento de Cristal que, de acordo com o IBGE, tem uma população de 7280 habitantes. Caso Cristal venha a crescer, seus habitantes (humanos e não-humanos), podem perturbar ainda mais os Mbyá que vivem na tekoá Tavaí.

Com o intuito de melhor ilustrar o modo como os Mbyá classificam diferentes 
Revista de Arqueologia Pública

paisagens de acordo com critérios que representam, ao mesmo tempo, feições ecológicas e significados mítico-cosmológicos, desenvolvi a tabela abaixo. Nesta tabela uso o máximo possível de classificações êmicas dos Mbyá, embora não descarte o uso de classificações éticas.

\begin{tabular}{|l|l|l|l|}
\hline Paisagem & Vegetação & Classificação & Entidades \\
\hline Kaáguy (mata) & $\begin{array}{l}\text { Mata Atlântica em } \\
\text { diversos graus de } \\
\text { preservação/degradação }\end{array}$ & Porã & $\begin{array}{l}\text { Karaí Mirí, } \\
\text { diversos Já, } \\
\text { outras. }\end{array}$ \\
\hline Inhu (campo) & $\begin{array}{l}\text { Campo de origem } \\
\text { antrópica, } \\
\text { principalmente } \\
\text { pastagens }\end{array}$ & Uaikuê & $\begin{array}{l}\text { Inhujáá, Tuku } \\
\text { Pararã í, outras }\end{array}$ \\
\hline Tetã (cidade) & $\begin{array}{l}\text { Árvores isoladas em } \\
\text { œnário urbano }\end{array}$ & Uaikuê & Tetẫá, outras \\
\hline
\end{tabular}

Tabela 1: Tabela comparativa de paisagens e entidades. Fonte: Orestes Jayme Mega, 2016.

Na tabela, uso termos como "paisagem", pelo qual expresso três diferentes tipos de ambientes, que são: ambientes "florestais" ou de vestígios de Mata Atlântica (ka'aguy); ambientes de campos antrópicos, principalmente pastagens (inhu) e ambientes urbanos grandes ou pequenos (tetã). Obviamente se trata de uma classificação reduzida, pois existem diversas subclassificações dentro do que pode ser considerado ka'aguy.

Pelo termo "vegetação", expresso as condições florísticas presentes nas diferentes paisagens. Contudo, é importante ressaltar que, devido às condições ambientais atuais, mesmo os locais com presença de um número reduzido de árvores já são considerados ka'aguy, tal como apontou-me meu principal interlocutor.

Pelo termo "classificação", expresso as categorias êmicas Mbyá: porã ("bom", "bonito", “adequado") e uaikuê (“ruim”, “feio”, “inadequado”). Esta classificação binária foi obtida em trabalho etnográfico entre os Mbyá residentes na tekoá Tavaí durante minhas atividades de campo. 


\section{Revista de Arqueologia Pública}

Pelo termo "entidades", expresso o conjunto de entes não-humanos que habitam as diferentes paisagens representadas na tabela. As entidades apresentadas, em minha interpretação, estão intimamente relacionadas com as paisagens e, por isso, são como que habitantes destas e, desta forma, podem ser interpretadas como elementos das paisagens.

Ainda de acordo com minha interpretação, conforme ocorrem mudanças na condição ambiental de uma determinada paisagem, tais como onde uma área de ka'aguy se transforme em uma área de inhu, as entidades da paisagem também mudam.

A tabela demonstra que as paisagens classificadas como uaikuê constituem a maioria dos ambientes no cenário atual de degradação ambiental. A tekoá Tavaí, assim como diversas outras tekoá, representam pontos vestigiais de paisagens porã em meio a uma grande dimensão de paisagens consideradas uaikuê.

É cada vez menor o número de paisagens que podem ser consideradas porã e, como afirma meu principal interlocutor, hoje qualquer apanhado de árvores já pode ser considerado como ka'aguy. A afirmação de meu interlocutor expressa as mudanças pelas quais a classificação das paisagens pelos Mbyá está passando devido ao crescimento das áreas de inhu e tetã.

Com o intuito de aprofundar a reflexão a respeito das transformações que as paisagens habitadas ou reivindicadas pelos Mbyá passaram, analiso as relações existentes entre os aspectos diacrônicos das paisagens, sejam estes aspectos materiais - tais como a ruína que nomeia a tekoá Tavaí, as áreas de pindoty que demarcam antigas ocupações Guarani, as áreas de mata em regeneração que demarcam as antigas áreas de inhu etc. -, sejam estes aspectos imateriais - como aqueles relacionados aos domínios de entidades sobre certas paisagens e as mudanças ecológicas pelas quais estas paisagens passaram.

É importante ressaltar que, da mesma forma que os Mbyá observam a preocupante expansão das áreas de inhu e tetã, também observam, obviamente em menor intensidade e também em contextos igualmente menores, a regeneração das áreas de ka'aguy. Portanto, é possível observar um "câmbio" das paisagens e das entidades que nelas vivem. Com este propósito, desenvolvi uma nova tabela. 


\begin{tabular}{|c|c|c|c|}
\hline Paisagem: & Transformada em: & $\begin{array}{l}\text { Câmbio de } \\
\text { entidades: }\end{array}$ & Câmbio de etnias: \\
\hline Kaáguy & inhu & $\begin{array}{c}\text { De Kaáguyjá e demais } \\
\text { entidades } \\
\text { relacionadas aos } \\
\text { Mbyá para Inhujá e } \\
\text { demais entidades } \\
\text { relacionadas aos } \\
\text { juruá }\end{array}$ & De Mbyá para Juruá \\
\hline Kaáguy & tetã & $\begin{array}{c}\text { De Kaáguyjá e demais } \\
\text { entidades } \\
\text { relacionadas aos } \\
\text { Mbyá para tetãjá e } \\
\text { demais entidades } \\
\text { relacionadas aos } \\
\text { juruá }\end{array}$ & De Mbyá para Juruá \\
\hline Inhu & kaáguy & $\begin{array}{l}\text { De Inhujá e demais } \\
\text { entidades } \\
\text { relacionadas aos } \\
\text { juruá para Kaáguyjá e } \\
\text { demais entidades } \\
\text { relacionadas aos } \\
\text { Mbyá }\end{array}$ & De Juruá para Mbyá \\
\hline
\end{tabular}

Tabela 2: Tabela de transformações de paisagens e câmbio de entidades. Fonte: Orestes Jayme Mega, 2016.

$\mathrm{Na}$ tabela demonstro como as transformações ocorridas nos aspectos materiais das paisagens são igualmente consideradas como câmbios em seus aspectos imateriais, relacionados às entidades que vivem nas paisagens.

Aqui pode-se levantar uma questão bastante complexa e que se configura como um ponto de contato entre a mitologia Mbyá, a crise ambiental e a presença cada vez mais 
constante dos juruá na vida Mbyá. A Mata Atlântica, entendida como a feição original do mundo na perspectiva da cosmo-ecologia Mbyá (SOUZA, 2009), está cada vez mais se reduzindo a espaços bastante restritos, pequenos bosques cercados de campos, cidades, parques industriais etc.

Em outras palavras, a Mata Atlântica está se tornando um conjunto de ywyraty kuery (bosques) disperso e cada vez mais raro. Tal situação desperta um profundo pessimismo entre os Mbyá, pois não apenas representa a perda de "ambientes", mas a perda de elementos intimamente relacionados aos ambientes, isto é, às entidades espirituais que neles vivem.

As áreas de inhu e tetã, ao crescerem e pressionarem as áreas de ka'aguy, também pressionam os espaços onde vivem as entidades relacionadas aos Mbyá. Neste sentido, talvez seja possível interpretar estas perdas não apenas como uma espécie de ecocídio, no qual a flora e fauna nativas são substituídas por flora e fauna alóctones, mas como uma espécie de etnocídio, em que toda uma cultura rica em elementos materiais e imateriais passa a estar ameaçada.

O mito de Tuku Pararã Í e outros relacionados com a expansão das áreas de inhu e tetã abrem a possibilidade de uma inversão de perspectiva, colocando o Mbyá para explicar o juruá.

O mito de Tuku Pararã Í, entendido como uma "grande narrativa" dos Mbyá capaz de dar uma explicação coerente a respeito das origens tanto das áreas de inhu quanto da agressividade juruá, contrapõe-se à "grande narrativa" brasileira da conquista territorial e do "progresso" trazido pelo colonizador.

Em outras palavras, os povos ameríndios também possuem seus saberes que visam explicar a emergência dos colonizadores europeus e dos impactos desta emergência sobre a paisagem de uma maneira que possa ser entendido, desvendado, analisado. $O$ instrumento que os Mbyá possuem para entender e explicar o juruá é o mito. No caso específico aqui apresentado, o mito de Tuku Pararã Í e os mitos a ele associados explicam uma característica do comportamento juruá que, devido às suas consequências, constitui, possivelmente, a mais detestável e perigosa de suas características: a agressividade ambiental.

Para o Mbyá, o juruá é uma criatura agressiva. As marcas de sua agressividade podem ser facilmente verificadas na expansão dos espaços por ele pedidos a Ñanderu, isto \begin{tabular}{|l|l|l|l|l|l|l|}
\hline (C) Rev. Arqueologia Pública & Campinas, SP & v.11 & n.1 & p.48 & Julho/2017 & ISSN 2237-8294
\end{tabular} 


\section{Revista de Arqueologia Pública}

é, o inhu. Como narrado no mito, o juruá "come" a mata e, desta forma, ele age de maneira similar a Tuku Pararã Í, devorando o espaço que, por desígnio de Nanderu, pertence aos Mbyá.

Portanto, a agressividade juruá não pode ser entendida apenas como uma agressividade territorial, onde o objetivo seria conquistar território sem modificar suas características ambientais. A agressividade juruá pode ser entendida como uma agressividade ambiental e até mesmo cósmica na medida em que não apenas domina as paisagens, mas as transforma, derrubando a ka'aguy e estabelecendo o inhu e perturbando a ordem cósmica estabelecida por Nanderu.

\section{AGRADECIMENTOS}

Agradeço à CAPES pela bolsa de estudo que tornou possível a pesquisa na Tekoá Tavaí.

\section{REFERÊNCIAS}

ALBERTI et al. "Worlds Otherwise": Archaeology, Anthropology, and Ontological Difference. Current Anthropology, Vol. 52, No. 6 (December 2011), p. 896-912.

CATAFESTO DE SOUZA. J. O. Os Mbyá-Guarani e os Impasses das Políticas no Sul do Brasil. Anais da VIII Reunião de Antropologia do Mercosul. Buenos Aires. 2009.

GARLET. I e ASSIS. V. Desterritoralização e Reterritorialização: A Compreensão do Território e da Mobilidade Mbyá-Guarani Através das Fontes Históricas. Revista Fronteiras, Dourados, MS, v. 11, n. 19, p. 15-46, jan./jun. 2009.

LADEIRA. M. I. Espaço Geográfico Guarani-Mbya: significado, constituição e uso. Tese de Doutorado. São Paulo: FFLCH-USP, 2001.

LITAIFF. A. As Divinas Palavras: Identidade Étnica dos Guarani-Mbyá. Florianópolis: Editora da UFSC, 1996.

PIERRI. D. C. O Perecível e o Imperecível: lógica do sensível e corporalidade no pensamento guarani-mbyá. Dissertação de mestrado. USP, 2013.

TEMPASS. M. C. "Quanto mais doce, melhor": Um estudo antropológico das práticas alimentares da doce sociedade Mbyá-Guarani. Tese de doutorado. UFRGS, 2010. 